Review Article

\title{
Maternal Deaths in India: A Review of Trends and Programmes
}

\author{
Cimil Babu', Molly Babu' \\ ${ }^{1}$ Professor, Holy Family College of Nursing (Affiliated to University of Delhi), Okhla Road, New Delhi, India. \\ ${ }^{2}$ Associate Professor, Department of Obstetrical Nursing, R.A.K. College of Nursing (Affiliated to University of Delhi), Lajpat \\ Nagar, New Delhi, India. \\ DOI: https://doi.org/10.24321/2454.325X.202113
}

\section{I $\quad \mathbf{N} \quad \mathbf{F} \quad \mathbf{O}$}

\author{
Corresponding Author: \\ Cimil Babu, Holy Family College of Nursing \\ (Affiliated to University of Delhi), Okhla Road, \\ New Delhi, India. \\ E-mail Id: \\ cimilbabu@gmail.com \\ Orcid Id: \\ https://orcid.org/0000-0002-4062-6302 \\ How to cite this article: \\ Babu C, Babu M. Maternal Deaths in India: A \\ Review of Trends and Programmes. Int J Preven \\ Curat Comm Med. 2021;7(3):17-21. \\ Date of Submission: 2021-07-06 \\ Date of Acceptance: 2021-09-28
}

\section{$\begin{array}{llllllllllllll}\mathbf{A} & \mathbf{B} & \mathbf{S} & \mathbf{T} & \mathbf{R} & \mathbf{A} & \mathbf{C} & \mathbf{T}\end{array}$}

High-quality services during childbirth in a health care facility reduce maternal morbidity and mortality. High maternal mortality in India is a critical concern. In an attempt to decrease the maternal mortality rate (MMR), the Government of India has launched many programmes. This article discusses the trends in maternal mortality in India with the inter-state disparities. As per Sample Registration System (SRS), MMR in India was estimated to be 556 in 1990, but globally it was only 385 at that time. India has achieved about a $77 \%$ reduction in maternal mortality compared to the global average of $43 \%$ between 2005 and 2017, but a huge inter-state disparity in maternal death still exists. Approximately $65 \%-75 \%$ of the estimated maternal deaths in India occur in a few states, including the eight Empowered Action Group (EAG) states (Bihar, Jharkhand, Madhya Pradesh, Chhattisgarh, Odisha, Rajasthan, Uttar Pradesh, and Uttarakhand), and Assam. For instance, the MMR reported for Assam (state which has the highest MMR) was 215 in 2017-18 which is five times higher than that of Kerala (43), which has the least MMR of all states. Most of the maternal deaths are due to direct causes and are largely preventable and treatable. There was a consistent reduction in MMR as a result of a number of interventions and programmes including Janani Suraksha Yojana (JSY) which helped in surging institutional deliveries.

Keywords: Maternal Mortality, Trends, Programmes, Disparity, Janani Suraksha Yojana

\section{Introduction}

High-quality services during delivery in a health facility reduce maternal morbidity and mortality. For a mother, the birth of a child should be a moment of joy. But for many, the moment of birth is often frightening. ${ }^{1}$ All women need access to skilled attendance during delivery. ${ }^{2}$ Maternal mortality is one of the main health indicators of any society. Complications during pregnancy and delivery are the leading causes of maternal deaths in developing countries. ${ }^{3}$ The maternal mortality ratio (MMR) is the number of maternal deaths during a given period per 100,000 live births.

The International Bill of Human Rights of 1948 in Article 25 stated that "Motherhood and childhood are entitled to special care and assistance". ${ }^{4}$ There was no clear attention to maternal deaths in international policies at that time and there were no concrete data on maternal deaths. Maternal 
mortality was considered a problem of poor countries. In 1978, Alma Ata Declaration drew attention towards primary health care including maternal and child health (but no direct reference was made to maternal mortality). ${ }^{5}$

In 1987, WHO launched the Safe Motherhood Initiative that attracted global attention towards maternal mortality. The goal was to reduce maternal mortality by half by the year 2000. The programme focused on the detection of high-risk pregnancies and the training of traditional birth attendants. ${ }^{6}$ Since the year 2000 , global attention has turned to the Millennium Development Goals (MDGs), developed after the Millennium Summit in New York (in 2000) that involved 189 nations as initial signatories. The fifth of the eight MDGs was to reduce MMR by $75 \%$ by 2015 and to achieve universal access to reproductive health. ${ }^{7}$

\section{Global Trends in Maternal Deaths}

Between 2000 and 2018 worldwide maternal deaths decreased, but with vast inequalities. Southern Asia achieved the greatest reduction of 59\%. Approximately $50 \%$ reduction occurred in four other regions: Central Asia, Eastern Asia, Europe, and Northern Africa. Sub Saharan Africa achieved a reduction of $38 \%$, However, accurate measurement of maternal mortality still remains a challenge and MMR in the least developed countries is still high. ${ }^{8}$ The five countries with the highest number of maternal deaths in 2015 were Nigeria $(58,000)$, India $(45,000)$, the Democratic Republic of Congo (22,000), Ethiopia (11,000), and Pakistan $(9,700) .{ }^{9}$ Although India has shown considerable progress, it has failed to achieve MDG 5 (MMR of 100 by 2015). Neighbouring countries like China, Sri Lanka, and Thailand had MMR 27, 30, and 20 respectively in 2015 as compared to 130 in India.

\section{Trends in Maternal Mortality in India}

Bhore Committee reported that MMR in India during the 1940s was around 2,000. ${ }^{5}$ As per Sample Registration System (SRS), MMR in India was over 800 during the 1970, over 500 during the 1980, and in 1990 it was more than $400 .^{4}$ Table 1 and Figure 1 shows that MMR in India has declined from 254 during 2004-2018. to 113 in 2016- 2018. ${ }^{1,4}$

Table I.Maternal Mortality in India2004-20 I 8)

\begin{tabular}{|c|c|}
\hline Year & MMR per $\mathbf{1 0 0 0 0 0}$ Live Births \\
\hline $2004-2006$ & 254 \\
\hline $2007-2009$ & 212 \\
\hline $2010-2012$ & 178 \\
\hline $2011-2013$ & 167 \\
\hline $2014-2016$ & 130 \\
\hline $2015-2017$ & 122 \\
\hline $2016-2018$ & 113 \\
\hline Source: SRS & \\
\hline
\end{tabular}


the number of institutional deliveries, maternal deaths, and JSY cash beneficiaries, for example, there were $67.8 \%$ institutional births during NFHS-4 in Uttar Pradesh and 84\% in Delhi. Many studies reported about the disparities among states. ${ }^{13,14}$ Paul $\mathrm{S}$ et al. found that the relative inequality in $\mathrm{MCH}$ utilisation declined across states during the period $2006-16 .{ }^{15}$ According to WHO, in $2018,75 \%$ of rural births and $89 \%$ of urban deliveries were supervised.

It is critical to examine whether the disparities are narrowing. The MMR range across states was computed as the difference between the MMRs of states with the highest and the lowest MMR values. During 2001-03, a 407-point difference was observed between the MMR of Uttar Pradesh/ Uttarakhand (highest) and that of Kerala (lowest). During 2010-12, the gap between the MMR of Assam (highest) and Kerala (lowest) was 262 points. Although the gaps between the extremes are reducing, the range ratio (ratio of the MMRs of the states with the highest and the lowest MMR values) has not changed. Now also MMR of the worst-performing state is almost five times more than that of the best-performing state. ${ }^{4}$ The magnitude of inter-state disparities still remains high (Table 2).

\section{Causes of Maternal Deaths}

According to UNICEF (2021), the causes of maternal deaths, especially direct causes, are well known and can mostly be prevented or treated. ${ }^{1}$ Understanding the causes of maternal death is essential for developing strategies related to MMR reduction. Under the International Classification of Diseases and Related Health Problems (ICD-10), the causes of maternal deaths are categorised broadly into direct and indirect causes. ${ }^{5}$ In 1985 , WHO reported that $63-80 \%$ of maternal deaths caused due to direct obstetric causes and $88-98 \%$ of all maternal deaths could probably have been prevented with proper handling. In India, poor coordination between levels in the delivery system, fragmentation of care, and mass illiteracy were identified as the causes of high MMR during that period. ${ }^{16}$

In 2003, a study conducted by ICMR (Indian Council of Medical Research) reported that the main causes of death among mothers were post-partum haemorrhage (17\%), septicaemia (13\%), and anaemia (13\%). About $70 \%$ of deaths occurred during the postnatal period followed by $24 \%$ during the antenatal period and $7 \%$ during childbirth. $45 \%$ of the deliveries were conducted by untrained dais. More than $60 \%$ of deaths occurred among SC, ST, and OBC mothers. ${ }^{17}$

According to UNICEF (2021), the major complications that account for nearly two-thirds of all maternal deaths are severe $\mathrm{PPH}$, infections, hypertension, complications from childbirth and abortions. ${ }^{1}$
Assam has the highest MMR among Indian states. A study by Kakoty and Das (2019) found that MMR in Assam has decreased linearly with an increase in the proportion of rural population and MMR increased with an increase in the proportion of anaemia. ${ }^{18}$

Horwood G et al. in their study, published in 2020, found that complications of pregnancy and medical comorbidities were the strongest risk factors for maternal death. ${ }^{12}$ Another study in 2020 by Hamal Mukesh et al. identified that economic status, caste/ ethnicity, education, gender, religion, and culture were the most important social determinants of maternal health in India. ${ }^{19}$

\section{National Programmes - A Road to Progress towards Preventing Maternal Deaths}

The Indian government has been launching many programmes in the past two decades to reduce maternal mortality.

India could achieve about $77 \%$ reduction in maternal mortality as compared to the global average of $43 \%$ between 2005 and 2017. ${ }^{20}$ According to WHO 2018, the proportion of institutional deliveries in public facilities has almost tripled (from 18\% in 2005 to $52 \%$ in 2016 and $79 \%$ in 2018). ${ }^{11}$. In 1992, the Child Survival and Safe Motherhood Programme (1992-1995) was launched, which focused on maternal health and mortality and covered all the districts of the country by $1997 .{ }^{20}$ The Reproductive and Child Health (RCH Phase I) Programme was launched in 1997 and $\mathrm{RCH}$ Phase II was launched in 2005.

WHO's global commemoration of World Health Day 2005 took place in New Delhi and the world health report 2005 - 'Make Every Mother and Child Count' - was launched on that day. Prime minister Dr Manmohan Singh met world leaders on that day and discussed maternal health issues. ${ }^{22}$

The National Rural Health Mission (NRHM) was launched in 2005 with special focus given to the EAG states. Under NRHM, numerous new initiatives were launched including the Janani Suraksha Yojana (JSY). The programmes identified ASHA (Accredited Social Health Activist) as a link person between mother and public health facilities. JSY has resulted in a surge in institutional deliveries since its launch. ${ }^{23}$

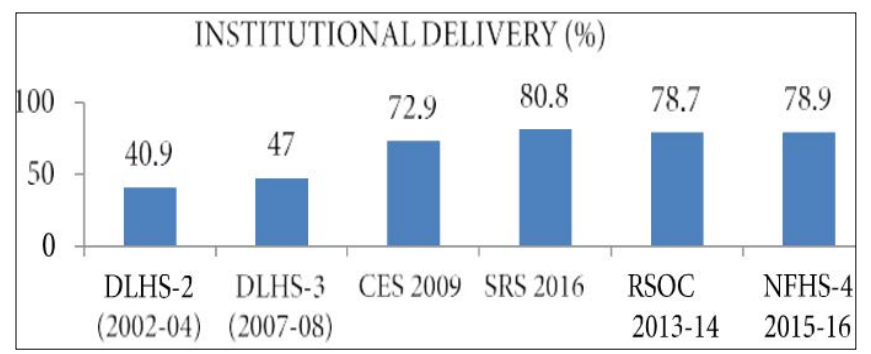

Figure 2.Trends in Institutional Delivery in India Source: Annual Report 2019-20, MoHFW25 
Maternal and Child Health (MCH) Wings with a bed capacity of 100/50/30 were established in District Hospitals/ SubDistrict Hospitals/ CHC-FRUs to reduce the caseloads and facilitate institutional deliveries at these facilities. ${ }^{23}$

The Government of India launched Janani Shishu Suraksha Karyakaram (JSSK) in 2011. With this scheme, all pregnant women delivering in public health facilities will have absolutely no expense delivery. ${ }^{24}$ According to the Annual report (MoHFW 2017-18), 32 states/ UTs have a free ambulance facility. ${ }^{24}$

In 2013, India launched RMNCH+A (Reproductive, Maternal, New-born, Child and Adolescent Health) approach to address the major causes of mortality among women and children. To improve registration and to track antenatal mothers, neonates, infants, and children by name for antenatal, intranatal, and postnatal care, and family planning and immunisation, a web-enabled Mother and Child Tracking System (MCTS) has been launched. ${ }^{24} \mathrm{~A}$ Mother and Child Protection (MCP) Card was issued by the Ministry of Women and Child Development in all states for monitoring $\mathrm{MCH}$ and nutrition interventions. ${ }^{23}$

Kilkari (meaning a baby's gurgle) is a mobile health education service that delivers free audio messages about pregnancy, delivery, and child care directly to families' mobile phones. Mobile Academy is a free audio training course for ASHA. ${ }^{23}$ Skill building through training programmes for all categories of service providers was implemented. ${ }^{23}$

Pradhan Mantri Surakshit Matritva Abhiyan (PMSMA), launched in June 2016, provides comprehensive and free of cost antenatal care on a fixed day (9th of every month). ${ }^{25}$ Another initiative, Pradhan Mantri Matri Vandana Yojana (PMMVY), a cash incentive scheme of INR 5000, was launched in 2017 for pregnant and lactating mothers for the first living child of the family. ${ }^{26}$

SUMAN-Surakshit Matritva Aashwasan was launched in 2019 with an aim to provide assured, dignified, respectful, and quality healthcare to women and newborns. ${ }^{27}$ LaQshya program (Labour room Quality improvement Initiative) was launched in 2017 to improve the quality of care in the labour room and maternity operation theatres. ${ }^{27}$ MAA (Mother's Absolute Affection) programme was launched in 2016 to promote breast feeding. ${ }^{28}$

MCTS/ RCH portal is used for capturing data of JSY beneficiaries and other services. ${ }^{27} \mathrm{NFHS}$ (The National Family Health Surveys) areconducted periodically by MoHFW to generate data on indicators related to maternal health.

Other important initiatives include the following: $:^{26}$

- $\quad$ Special provision of birthwaiting homes under NHM in tribal areas

- Maternal Death Surveillance and Response (MDSR) to take corrective action for averting maternal deaths

- Operational guidelines for universal screening of gestational diabetes mellitus and hypothyroidism during pregnancy

- Promotion of birth companion

- Monthly Village Health and Nutrition Days (VHND) at Anganwadi centres

- Distribution of iron and folic acid supplements to pregnant, lactating women, and adolescent girls under the National Iron+ Initiative

- Conduction of regular IEC/ BCC programmes

- 'Delivery Points' for comprehensive RMNCH+A services

The National Health Policy (2017) strongly recommends strengthening of health systems to prevent and manage maternal complications, and to ensure continuity of care and emergency services. ${ }^{29,27}$

India has committed to the UN target of the Sustainable Development Goals (SDGs) of MMR 70 by 2030. This cannot be achieved without maternal, newborn, and child health coverage for allAs announced during the Union Budget for the year 2020-21, a Task Force has been constituted to examine the correlation of age of marriage and motherhood with health, well-being, and nutritional status of mother and child. ${ }^{26}$

\section{Conclusion}

Independent India has come far in the past seven decades and has achieved remarkable success in reducing MMR due to the combined global, national, and state efforts. The Government of India has been launching many programmes including Janani Suraksha Yojana during the last two decades. We have seen remarkable growth in institutional deliveries and other maternal health indicators, but it still is a long way to go.

\section{Conflict of Interest: None}

\section{References}

1. UNICEF [Internet]. Maternal health: UNICEF's concerted action to increase access to quality maternal health services; 2021. Available from: https://www.unicef. org/india/what-we-do/maternal-health Accessed on 18/9/ 21

2. Healthy People [Internet]. Maternal, infant, and child health; 2020. Available from: https://www. healthypeople.gov/2020/topics-objectives/topic/ maternal-infant-and-child-health Accessed on 29/09/2021

3. The International Bill of Human Rights; 1948. Available from: https://www.ohchr.org/documents/publications/ compilation1.1en.pd Accessed on 02/07/2021

4. Joe W, Sharma S, Sharma J, Shanta YM, Ramanathan M, Mishra US, Sri BS. Maternal mortality in India: a review of trends and patterns. IEG Working Paper No. 
353; 2015. [Google Scholar]

5. WHO. World Health Day Safe Motherhood, https:// www.who.int/docstore/world-health-day/en/ documents1998/whd98.pdf Accessed 5/08/2021

6. Kyei-Nimakoh $M$, Carolan-Olah M, McCann TV. Millennium development Goal 5: progress and challenges in reducing maternal deaths in Ghana. BMC Pregnancy Childbirth. 2016;16:51. [PubMed] [Google Scholar]

7. Maternal Health Task Force. Sustainable Development Goals and Maternal Mortality https://www.mhtf. org/topics/the-sustainable-development-goals-andmaternal-mortality/ Accessed on 20/08/2021

8. WHO, UNICEF, UNPFA, Worl Bank. Trends in Maternal Mortality https://www.who.int/reproductivehealth/ publications/maternal-mortality-2000-2017/en/ Accessed on 25/08/2021

9. Zodpey SP, Negandhi PH. Tracking India's progress in health sector after 70 years of independence. Indian J Public Health. 2018;62(1):1-3. [PubMed] [Google Scholar]

10. MoHFW [Internet]. Maternal and adolescent health care. Annual Report 2017-18; 2018 [cited 2021 Aug 16]. Available from: https://main.mohfw.gov.in/sites/ default/files/03Chapter.pdf

11. Ministry of Women and Child Development, Maternal Mortality Rate.202, https://www.pib.gov. in/PressReleasePage.aspx?PRID=1697441 Accessed 21/08/2021

12. Horwood G, Opondo C, Choudhury SS, Rani A, Nair M. Risk factors for maternal mortality among 1.9 million women in nine empowered action group states in India: secondary analysis of Annual Health Survey data. BMJ Open. 2020;10(8):e038910. [PubMed] [Google Scholar]

13. MoHFW [Internet]. National Family Health Survey -4, 2015-16, State Fact Sheet, Uttar Pradesh. Available from: http://rchiips.org/nfhs/pdf/NFHS4/UP_FactSheet.pdf Accessed date 2/08/2021

14. State Fact Sheet, NCT Delhi, NFHS1http://rchiips.org/ nfhs/nfhs1.shtml Accessed on 2/08/21

15. Paul S, Paul S, James KS. Universalisation versus targeting in maternal and child health care provisioning: evidence from India. SSM Popul Health. 2019;9:100502. [PubMed] [Google Scholar]

16. Prakash A, Swain S, Seth A. Maternal mortality in India: current status and strategies for reduction. Indian Pediatr. 1991 Dec;28(12):1395-400. [PubMed] [Google Scholar]

17. ICMR [Internet]. Estimates of maternal mortality ratios in India and its states a pilot study. Available from: https://main.icmr.nic.in/sites/default/files/reports/ Final_Pilot_Report.pdf Accessed date 20/09/21

18. Kakoty SD, Das J. Factors associated with inter-district variation of maternal mortality in Assam. Int J Med Sci Public Health. 2020;9(2):163-9. [Google Scholar]

19. Hamal M, Dieleman M, Brouwere VD, Buning TC. Social determinants of maternal health: a scoping review of factors influencing maternal mortality and maternal health service use in India. Public Health Rev. 2020;41:13. [PubMed] [Google Scholar]

20. Bhatia M, Dwivedi LK, Banerjee K, Bansal A, Ranjan $M$, Dixit P. Pro-poor policies and improvements in maternal health outcomes in India. BMC Pregnancy Childbirth. 2021;21(1):389. [PubMed] [Google Scholar]

21. O'Neil S, Naeve K, Ved R. An examination of the maternal health quality of care landscape in India [Internet]; 2017. Available from: https://core.ac.uk/ reader/89473010 Accessed on 21/08/2021

22. WHO [Internet]. India hosts global celebration of World Health Day 2005. Available from: https://www.who. int/world-health-day/previous/2005/activities/global_ celebration/en/ Accessed on 20/08/2021

23. MoHFW [Internet]. Maternal health programme. Annual Report 2013-14. Available from: https:// main.mohfw.gov.in/sites/default/files/Chapter415. pdf Accessed on 20/07/2021

24. MoHFW. A strategic Approach to RMNCH+A https:// nhm.gov.in/images/pdf/RMNCH+A/RMNCH+A_ Strategy.pdf Accessed on 2/08/2021

25. NHM [Internet]. Pradhan Mantri Surakshit Matritva Abhiyan; 2021. Available from: https://pmsma.nhp. gov.in/ Accessed on 25/08/2021

26. Ministry of Women and Child Development [Internet]. Reduction in maternal mortality rate; 2020 Sep 8. Available from: https://pib.gov.in/ PressReleaselframePage.aspx?PRID=1656242 Accessed on $5 / 08 / 2021$

27. Annual Report, MOHFW, 2019-20 https://main.mohfw. gov.in/sites/default/files/Annual\%20Report\%2020192020\%20English.pdf Accessed on 20/08/2021

28. NHP [Internet]. MAA (Mothers' Absolute Affection) programme for infant and young child feeding. Available from: https://www.nhp.gov.in/maa(mothers\%E2\%80\%99-absolute-affection)-programmefor-infant-and-young-child-feeding_pg Accessed on 2/08/21

29. NHP [Internet]. National Health Policy 2017. Available from: https://www.nhp.gov.in/nhpfiles/national_ health_policy_2017.pdf Accessed on 3/08/2021

30. WHO [Internet]. Maternal Health; 2020. Available from: Accessesed on 2/08/21. https://www.who.int/ health-topics/maternal-health\#tab=tab_2 